\title{
Nurses' views about tuberculosis patients' discharge plan at Moses Kotane in the North-West Province
}

\author{
SF Motsomane, Mcur \\ Department of Nursing Science, University of Pretoria \\ MD Peu, Mcur \\ Department of Nursing Science, University of Pretoria
}

Key words: Tuberculosis (TB), hospital discharge plan, HIV/AIDS, DOTS, MDR, TB education, Traditional healers.

\section{Correspondence address:}

Mrs MD Peu

Department of Nursing Science P.O.BOX 667

Faculty of Health Care Sciences

University of Pretoria

Pretoria

0001

Tel : (012) 354-2133

Fax : (012) 354-1490

E-mail : mpeu@postillion.up.ac.za

\section{Abstract: Curationis 31(1): 59-67}

The purpose of this study was to explore and describe the opinions of nurses working with tuberculosis (TB) patients regarding hospital discharge plans at Moses Kotane in North-West, South Africa.

\section{Method}

A qualitative, exploratory and descriptive study was conducted with these nurses. The population involved registered nurses working with TB patients for more than two years. The population was purposely selected. Focus group interviews were conducted to collect data from this population. The research process was guided by the research question: What are the opinions of nurses working with TB patients regarding hospital discharge plans at Moses Kotane in the North-West Province? The group moderator guided the participants throughout the interviews in which the central research question was posed. Tesch's qualitative method of data analysis was used to analyse the data obtained.

Findings

Subcategories and categories, and the following themes emerged during the data analysis: the need for education and involvement, the co-existence of TB and HIV/ Aids infections and the knowledge of continuous laboratory investigations. The participants discussed the suggestions and solutions for effective hospital discharge plans. The research findings could assist in the improvement of existing hospital discharge plans at Moses Kotane District.

\section{Conclusions}

The results revealed both positive and negative opinions regarding discharge plans. The data were classified into themes, categories and subcategories. The participants' suggestions regarding discharge plans were addressed and discussed. Finally, recommendations were disseminated to concerned authorities.

\section{Introduction and}

\section{background of the study}

District hospitals in the North-West Province of South Africa, cater for rural communities with illnesses and diseases, such as psychiatric illnesses, minor ailments and tuberculosis (TB). In these hospitals, discharge planning begins the day the patient is admitted. It involves an assessment of the situation into which the patient is moving and the needs related to the patient's condition, imposed by this situation (Phipps and Sands 2003:155). Although discharge plans are used, TB patients continue to relapse on their treatment.

Discharge planning is a process that involves the patient, family members and members of the multidisciplinary healthcare team. In the case of TB 
patients, this includes the nurses working with the patients (Stanhope \& Lancaster, 2000:382). Furthermore, discharge planning is needed to ensure the continuity of care as patients move from one segment of the healthcare system to another. The multidisciplinary healthcare team has to plan in order to prevent (further) complications in the patient's condition. It is therefore important to investigate the opinions of nurses working with TB patients regarding a discharge plan that affects not only the health of the individual TB patient, but also the prevalence of the disease.

Stanhope and Lancaster (2000:382) state that discharge planning prepares the patient for the next phase of care by means of organised planning and coordination of resources. Patients suffering from TB are informed of relevant resources available for the continuity of their care after being discharged from the hospital (Vlok, 2006: 534-535). However, some patients discontinue their treatment. As a result, patients have to be readmitted after two to three months, a frequent occurrence at district hospitals in the North-West. There are an estimated 9557 cases of TB in the NorthWest Province including George Stegmann Hospital in the Moses Kotane District and $25 \%$ of TB patients are HIV positive (South Africa, Department of Health, 2002:1). The incidence of TB per 100000 people is 271 in the respective province. In South Africa, City of Cape Town alone, 22999 people were infected with TB in 2003 (Joubert \& Ehrlich 2007:180).

In addition to this, nurses working with TB patients are faced with the following challenges:

- Patients relapse;

- Discontinuation of treatment by patient;

- $\quad$ Diverse attitudes and viewpoints regarding the relationship between TB and the human immunodeficiency virus/acquired immunodeficiency syndrome (HIV/AIDS);

- Insufficient medication; poor coordination and lack of cooperation between members of the healthcare team

These challenges could influence the positive effect, in reducing $T B$ as a health problem, of a hospital discharge plan for TB patients.

The South African National Tuberculosis Association (SANTA, 2001:6) stated that $\mathrm{TB}$, as a social and health problem, is curable, even with the additional effect of HIV/AIDS. However, socioeconomic factors such as poverty and unemployment adversely affect the prognosis of TB being curable. Unemployed TB patients, especially those living far from clinics, might be unable to pay for transport to health services (SANTA, 2001:6). People in poorer communities tend to be ignorant of their health status, the communicability of TB, curative aspects and compliance with treatment. Nurses, as members of the multidisciplinary team working with TB patients, assess clients for referral. Integrating the ideas or suggestions of nurses working with TB patients into a hospital discharge plan at district hospitals could contribute toward a reduction in TB statistics in South Africa.

Patients, who suffered relapses as a result of discontinuation of treatment or other reasons, are continuously readmitted to district hospitals. Individuals with diverse beliefs and traditions consult indigenous healthcare services within the communities about their ill health. Their cultural values and beliefs affect their compliance with conventional medical treatment. In these communities, TB is known as sejeso, resembling signs and symptoms of TB (Barnhart, 1996:179). Patients usually visit traditional healers for further management of their ill health. In her study of the attitudes of traditional healers toward TB patients at $\mathrm{Ga}$ Rankuwa Hospital, Moloantoa in Vlok (2006:524) provides useful information on the disease. She indicates that traditional beliefs and attitudes persist in these communities. Moloantoa suggests that effective communication could promote improvement in nurse-patient relationships. By incorporating the suggestions of nurses working with TB patients into an effective discharge plan for TB patients, the number of defaulters and the number of patients who discontinue treatment could be reduced

Proper discharge planning regarding TB patients should include the provision of sufficient information by healthcare workers to ensure that patients have knowledge of and insight into their illness. A discharge plan for a TB patient should focus on the total well-being of the patient. Nurses should be given the opportunity to sit down and discuss the situation with the patient, to plan ways and methods of coping with the problems that may arise, and to make realistic future plans (Phipps and Sands, 2003:156).

The needs of the patient should be assessed before discharge occurs ensuring that continuity of care is maintained during and after transfer from the healthcare facility to another setting (Phipps and Sands, 2003:156).

The care providers need information about the patient, treatment and followup visits to assist in implementing the TB patients' treatment and follow up visit (Clemen-Stone, McGuire and Eigsti 2002:313-314). Stanhope and Lancaster (2000:843) regard discharge planning as continuity of care in which the multidisciplinary team prevent further complications of the patient's condition and promote his/her health. A discharge plan ultimately promotes selfobservation, self-determination and selfrespect in a TB patient.

\section{Problem statement}

The George Stegmann Hospital statistics (Department of Health, 2006:1-10 and 2006:1-10) indicate frequent readinissions of TB patients to district hospitals. There were 1300 patients who were admitted in a hospital, 83 cases of relapses were diagnosed and 6 patients were diagnosed as MDR in 2006 (Ibid 2006:6). Patients are often unable to continue with their prescribed TB treatment. Treatment is prescribed by healthcare personnel and collected by patients, but not continued or completed. Therefore, a discharge plan for TB patients needs to be designed and evaluated for progress. The research question for this research was: What are the views of nurses working with TB patients regarding a hospital discharge plan for these patients in the George Stegmann Hospital in the Moses Kotane Local Municipality in the North-West Province, South Africa?

\section{Significance of the study}

Research findings on the views of nurses working with TB patients regarding a hospital discharge plan for these patients at George Stegmann Hospital in the Moses Kotane Local Municipality in the 
North-West could enhance TB patients' hospital discharge plans. The findings might also assist with the reduction of relapses and multidrug resistant TB patients.

\section{Aim of the study}

The aim of the study was to explore and describe the views of nurses working with TB patients regarding the hospital discharge plan for TB patients at George Stegmann Hospital in the Moses Kotane District.

\section{Definition of concepts}

\section{Defaulter}

A TB defaulter is a person who has not attended therapy for two consecutive months or who has had less than $75 \%$ of doses during the six-month therapy period (Vlok, 2006:535).

\section{- $\quad$ Discharge plan}

A discharge plan involves identifying the patient's needs and making plans regarding continued care following discharge from a healthcare institution (Lundy and Janes, 2001:902-903).

\section{- Relapse}

TB relapse denotes recurrence following successful treatment of TB (Karim and Karim, 2005:437).

\section{- Tuberculosis}

The bacillus Mycobacterium Tuberculosis causes this chronic, infectious disease (Allender and Spradley, 2005:206).

\section{Research design}

An exploratory and descriptive qualitative research design was adopted to conduct research into the views of nurses, working with TB patients, regarding discharge planning for $\mathrm{TB}$ patients at George Stegmann Hospital in the Moses Kotane Local Municipality district.

\section{Population and sampling}

The population in this study consisted of all nurses working directly with TB patients at the George Stegmann Hospital in the Moses Kotane Local Municipality district, North-West Province. The study population for this research involved nurses who had two or more years of experience working with TB patients. These nurses had tremendous experience and relevant information in working with TB patients in the province. One focus group consisting of six participants was utilised. They had the confidence to give information on TB patients, friends, families and other community members.

The participants of this study were purposely sampled and consciously selected to include those nurses with relevant information on TB. Sampling refers to the process of selecting a portion of the population to represent the entire population (Polit et al., 2001:234). A selection criteria for this study was nurses who had at least 2 years experience working with TB patients. Burns and Grove (2003:374) define selection criteria as the selection of typical individuals in relation to the phenomenon under study. Babbie and Mouton (2007:166) add that purposive sampling is a strategy in which the researcher's knowledge of the population is used to select the cases to be included in the sample. The participants were purposively selected because they possessed the relevant information required for the study.

\section{Ethical considerations}

Permission to conduct the research was obtained from the district hospital authorities and the informed consent and nurse working with TB patients as participants were given explanations on the purpose and nature of the research. Ethical principles were adhered to, and participants were ensured of protection from harm. The researcher considered the sensitivity of participants when setting questions (Polit et al, 2001:78). Participants were respected for human dignity. This included the right to selfdetermination and the right to full participation. The researcher protected the rights of participants throughout the research process. The participants were protected from discomfort and harm. Their rights to anonymity and confidentiality were ensured. The participants' privacy was ensured. The numbers were used as names to address the participants during the research process.

The right to self-determination was respected during the research process. Self-determination was based on the ethical principle of respect for persons, which stated that humans are capable of self-determination (Polit et al, 2001:78). Subjects were informed about the nature of the study and the freedom to choose whether to participate or not. Subjects had the right to withdraw from the study without any penalty.

\section{Data collection and instrument}

Data were obtained from nurses working with TB patients by means of focus group interviews. Six participants were involved in a focus group interviews. A focus group interview is described as a purposive discussion of a specific topic or related topics, which takes place between eight to ten individuals with similar backgrounds and common interests (De Vos, 2001:314 and Bless and Smith 2000: 110). The group's interaction during this study consisted of verbal and non-verbal communication and interplay of perceptions and opinions, which stimulated the discussion without necessarily modifying or changing the ideas and opinions of participating individuals (De Vos. 2001:314).

In this study, six participants were involved in a focus group discussion. A focus group interview was conducted with the aid of a tape recorder. The language of choice for interviews was English because the participants were fluent with English language. The use of a single source of data collection was not sufficient in qualitative research; therefore, a tape recorder added value to the study. Two focus group sessions were conducted because the researcher had to reach data saturation.

After the interview, the researcher thanked the participants and gave them a chance to give feedback about their experiences during the interview. The participants were given refreshment to allay any anxiety.

\section{Data analysis}

Qualitative methods were used to analyse the data. Qualitative data analysis is an active and interactive process, especially at the interpretive end of the analysing style continuum (Polit et al., 2001:383). In this research, the Tesch method of data analysis was followed (Tesch 1990 in Creswell 2003:192). This method involves following a series of steps in order to analyse the data. In order to do this, qualitative coding methods were employed. The data were analysed in the language (English) in which the interviews were conducted. All 
transcripts of two focus group sessions were carefully read in order to get a holistic overview. Thoughts were written down as they occurred. The topics were abbreviated as codes, and the codes were written on the appropriate side of the text. A final decision was made for each category.

\section{Measures to ensure trustworthiness}

The trustworthiness of this research was ensured through confirmability, credibility, transferability and dependability (Lincoln \& Guba (1985:301) in Polit et al. 2001:312).

\section{Confirmability}

Confirmability refers to the objectivity or neutrality of the data such that two or more independent people could agree about the data's meaning (Polit et al, 2001:315). In this study, confirmability was ensured through researcher objectivity and audit trail. The researcher remained objective throughout. The records made during data collection, including observations were kept and made available for future reference, scrutiny and confirmation.

\section{Credibility}

Credibility addresses the question as to whether the research has established confidence in the findings. The credibility of qualitative data and the resulting findings is the aspect of data quality on which most methodological attention has focused (Polit et al., 2001:313). Polit et al. (2001:313) cite Lincoln and Guba (1985:301) who suggest a variety of techniques, such as prolonged engagement, persistent observation, triangulation and member checking, for improving the credibility of qualitative research.

The researcher was engaged for a prolonged period with the participants. The researcher studied the culture of the participants and spent time with them. Trust and rapport was established during the collection of data. The participants were free to answer the research question without fear. The moderator conducted the interview so that the researcher was able to make note of observations during the interview. The moderator clarified the research question for the participants by simplifying or putting it in a different manner.
In Polit et al. (2001:313) and Babbie and Mouton (2007:275) states that triangulation is a method used to improve the likelihood of qualitative findings being credible. Triangulation refers to the use of multiple referents to draw conclusions about what constitutes the truth (Polit et al., 2001:313). In this study, the researcher used observations, a tape recorder and field notes to ensure credibility of data. The researcher replayed the tape recordings after each discussion so that the participants could listen to what they had discussed or how they had contributed to the study. The participants were followed up to verify the findings of the study to increases the confidence of the participants. The member check also increased the confidence of the participants. Persistent observation, as described by Lincoln and Guba, in Polit et al. (2001:313), was ensured when the researcher focused on the aspects of a situation that are relevant to the phenomena being studied.

\section{Transferability}

In Lincoln and Guba's framework, transferability refers essentially to the generalisability of the data (Polit et al., 2001:316). In this study, because generalisability to other situation will pose an obstacle, therefore the researcher provided the reader with the description of the background of the study, methodology as well as the information of participants involved. Other researchers will then utilise the relevant parts of this study.

\section{Dependability}

The dependability of qualitative data refers to the stability of data over time and conditions (Polit et al., 2001:315). In this study, the participants were selected and described. The data gathering methods, analysis and the findings of the study were described to ensure dependability of the study.

\section{Discussion of results and literature control}

Four themes, namely the need for education, the need for involvement, the co-existence of TB and HIV infections, and the knowledge of continuous laboratory investigations, emerged during the data analysis (see table 1 below). Literature relevant to the themes, categories and subcategories was used to control or verify the findings.

\section{Theme 1: Need for education}

The first theme that emerged was the need for education about TB. Various categories, namely TB patients, families of TB patients, teachers of children suffering from $\mathrm{TB}$ and hospital nurses.

\section{Category 1: TB patients}

Three subcategories, namely side effects of drugs, MDR and drug interaction, emerged from the category of TB patients, which emerged from the theme of the need for education.

\section{- $\quad$ Side effects}

The participants in the focus group all agreed that patient education must be incorporated into the discharge plan of TB patients. Several issues were emphasised as being important in this education, such as the side effects of TB drugs.

The following quotations are relevant: "You should teach the patient about the side effects like vomiting and allergic reactions." "They might experience things like yellow eyes and the urine turning yellow ... but these should not make them stop taking the treatment."

\section{- $\quad$ Multi-drug resistance (MDR)}

Participants mentioned the need to inform patients about the phenomenon of MDR and advise them about the benefits of compliance to medication. This was expressed as following:

"With MDR it is very rare that the patient gets well; most die from TB." "Once a patient has been diagnosed with MDR, the relatives should come for tests as they are now contacts."

\section{- Drug interaction}

Participants agreed that the discharge plan must include the education of the TB patient with regard to drug interactions.

They mentioned that:

"The patients, especially women, must know that TB treatment weakens the effectiveness of family planning drugs, thus they might need to use an intrauterine device (IUD) instead "The TB patient must report to all practitioners during consultation that they are on $T B$ treatment."

Pearson (2002:1090) supports the need 


\begin{tabular}{|c|c|c|}
\hline Theme & Categories & Subcategories \\
\hline \multirow[t]{4}{*}{ 1. Need for education about $\mathrm{TB}$} & 1.1 TB patients & $\begin{array}{l}\text { a. Side effects of drugs } \\
\text { b. Multi-drug resistance (MDR) } \\
\text { c. Drug interaction }\end{array}$ \\
\hline & 1.2 Families of the TB patient & $\begin{array}{l}\text { a. DOTS (Direct Observation Therapy) } \\
\text { b. Dehydration effects of enema }\end{array}$ \\
\hline & $\begin{array}{l}\text { 1.3 Teachers of children suffering from } \\
\text { TB }\end{array}$ & a. DOTS \\
\hline & 1.4 Hospital nurses & $\begin{array}{l}\text { a. DOTS } \\
\text { b. Discharge plan commences }\end{array}$ \\
\hline \multirow[t]{4}{*}{ 2. Need for involvement } & 2.1 Family of patient & a. Provision of good diet \\
\hline & 2.2 Social worker & a. Assessment for discharge grant \\
\hline & 2.3 School & a. Emotional support \\
\hline & 2.4 Traditional healers & a. Encourage compliance \\
\hline \multirow[t]{2}{*}{ 3. Co-existence of TB and HIV infections } & 3.1 TB patients & a. Emotional support by nurses \\
\hline & 3.2 Breast-feeding & $\begin{array}{l}\text { a. Knowledge about treatment } \\
\text { effectiveness }\end{array}$ \\
\hline $\begin{array}{l}\text { 4. Knowledge of continuous laboratory } \\
\text { investigations }\end{array}$ & $\begin{array}{l}\text { 4.1 Nurses } \\
\text { 4.2 TB patients and families }\end{array}$ & $\begin{array}{l}\text { a. Inform patient and their significant } \\
\text { other } \\
\text { a. Blood, sputum and x-ray tests }\end{array}$ \\
\hline
\end{tabular}

for patient education in aspects of TB medication, such as, if a patient experiences trouble with swallowing the drugs, they can be mixed with soft foods. The patient must be urged to comply with the prescribed regime, and not miss doses or discontinue drug intake without medical approval.

Patients with nausea, vomiting or other gastro-intestinal upsets should be advised to take drugs with food. Pearson (2002:1090) further states that urine and other body fluids may become discoloured, and patients should be cautioned that their clothes and soft contact lenses may become permanently discoloured.

Shannon, Wilson and Stang (2004:1083) add that patients should be educated that food may be useful in preventing gastrointestinal upsets. Schilling and Cann (2003:389) suggest that patients should be told of the benefits of plenty of rest. It is also important to eat balanced meals to promote recovery. Schilling and Cann
(2003:389) further support the participants' emphasis on the need for patient education with regard to adverse side effects and the reporting of these effects.

According to Schilling and Cann (2003:389), people who have been exposed to a patient with MDR TB need to be tested and prophylactic measures taken. Therefore, before any medication regime is initiated, the patient must be tested for HIV/AIDS for purposes of exclusion, as these patients can often end up with MDR (Kozier, Erb, German \& Snyder, 2004:88).

Category 2: Families of the TB patients Families of the TB patient emerged as the second category in the theme of the need for education. The internationally recognised TB control strategy, DOTS, emerged from this category.

\section{- DOTS}

Participants expressed the importance of educating the families of TB patients about DOTS. The following quotes are relevant:

"The family must know' about the green card." "The patient should always carry his/her green card like an identity document." "The teachers can supervise treatment of the scholars and even record in the green card." "It must be started in the hospital by nurses, and be continued after discharge."

\section{- Dehydration effects of enema}

According to the participants, the families of TB patients should be warned against the dehydration effects of enemas that are sometimes prescribed by traditional healers:

"And now, when we pick up ... the patient from the hospital, who is feeling better, we should also advise them not to consult traditional healer."

The participants of this study emphasised the need to educate patients 
about the dehydrating effects of traditional medicines, particularly enemas. Mulder (2004:334) confirms that enemas cause imbalances between fluid intake and output, and therefore precautionary measures should be taken when prescribing medicines for TB. The author further mentions that fluid imbalances occur when the compensation mechanisms of the body are incapable of maintaining a homeostatic balance. Abnormal loss of body fluid in the case of administration of enemas causes diarrhoea and, later, body weakness.

\section{Category 3: Teachers of children suffering from TB}

The third category that emerged from the theme of the need for education is teachers of children suffering from TB. This category also emerged in the subcategory of DOTS.

\section{- DOTS}

The participants involved in the study emphasised that:

"DOTS can be taught by the clinic sister. They should record on the green chart on daily basis until the patient goes for review or check up."

The participants of this study indicated that the DOTS programme provides a solution to TB control. The South African Department of Health in its Tuberculosis Control Programme Practical Guidelines (South Africa, Department of Health, 2000b:9), supports the DOTS short course as a break-through that is increasingly providing solutions to the control of the TB epidemic in South Africa.

This document further mentions that individuals from different sectors have a major role to play in the effective treatment of TB. All healthcare providers should use this programme in the management of TB. According to SANTA (2001:7), DOTS is the most effective strategy available for controlling the TB epidemic. It is thus the Government's commitment to sustain TB control activities (South Africa, Department of Health, 2005:22).

According to Allender and Spradley (2005:211), DOTS needs sustained political commitment, with the government of nations recognising the long-term benefits of providing the resources and staff necessary to ensure its proper implementation. DOTS therapy should be implemented for all patients, making use of community-based health workers who meet with patients in their homes, at their jobs or at other local venues.

\section{Category 4: Hospital nurses}

Hospital nurses emerged as the fourth category in the theme of the need for education. This category was further subdivided into DOTS and discharge plan commences.

\section{- $\quad$ DOTS}

Participants once again emphasised the importance of the DOTS strategy.

The following quote is relevant:

"Direct Observation Therapy Short course is started in the hospital by the nurses and immediately when the patient is discharged. The relatives will be invited and taught about DOTS and they must supervise the patient at home."

\section{- Discharge plan commences}

According to the participants, the discharge plan commences as soon as the patient is admitted to hospital.

"Discharge plan starts immediately after the admission of the patient. The relatives are to be invited and to be taught about DOTS. They will be informed about the DOTS supporters who are volunteers."

Pillitteri (2003:1037) argues that discharge planning is an important link in the patient's move from hospital to home. If a discharge plan were to be well developed, TB patients would not relapse but rather comply with their treatment. Stanhope and Lancaster (2000:382) add that a discharge plan is part of the continuous healthcare process and prepares the patient for the next phase of care. However, it is important that all health institutions have a comprehensive discharge plan in order to enhance the patients' prognosis. To achieve this plan, DOTS strategy should always be observed.

\section{Theme 2: Need for involvement}

The second theme that emerged was the need for involvement. The categories are: family of patients, social worker, school and traditional healers.

\section{Category 1: Family of patient}

The family of the patient emerged as the first category in the theme of the need for involvement. The provision of a good diet emerged from the category of family of the patient.

\section{- $\quad$ Provision of good diet}

All participants recognised the need for family involvement when planning for a TB patient's discharge. They mentioned that the family, as well as other role players, should be involved. The family must provide a well balanced diet for the patient. This was expressed as follows:

"They must be encouraged to grow' a vegetable garden because food is very expensive to buy."

Family members, as well as friends, play an important role with regard to the treatment of the patient. Lewis et al. (2004:604) indicate that family members or friends may help the client to eat correctly and maintain the required lifestyle changes. Family members should motivate the patient to adhere to the prescribed treatment in order to prevent the emergence of resistant strains of TB. Pearson (2002:1091) adds that family members should encourage the patient to promptly report any sign of flu, rash or itching of the skin when they are on TB treatment. Kozier et al. (2004:454) urge family members to be involved in the care of the patient, especially during the course of TB treatment and during preparations of food. These, in turn, ensure capacity building for the patients. Family members should support patients in not allowing their personal lives to become affected by the disease (Van Wyk 2005: 46). Family members also need to inform TB patients of any health awareness days regarding TB. On the TB awareness day, the family should attend the function with the patient.

\section{Category 2: Social worker}

The social worker emerged as the second category in the theme of the need for involvement specifically for organising a discharge grant for the TB patient. The participants expressed this as following: "The social worker must be involved from the word go ..." "The poor and needy patients must be assisted by means of social grants."

A social worker is a professional individual who provides the needy community with social relief. SANTA (2001:19) states that a social worker assists with grants and establishes 
community development with self-help projects, such as gardening, sewing, candle-making and brick-making. Kibel and Wagstaff (2003:540) mention that there exists a lobby that all children with disabilities and chronic illnesses, as well as their families, should be eligible for grants, as families incur extra expenses, such as visits to health centres, special clothing, loss of income, food and as a result of not being able to work because of caring for such children.

\section{Category 3: School}

School emerged as the third category in the theme of the need for involvement. The participants identified the need for schools to be involved in discharge plans in order for them to emotionally support young TB patients.

The school is an institution that can contribute to the progress of TB programmes. Teachers should emotionally support those who are sick, and young children who are taking and complying with treatment. Wong (2003:12) agrees that these patients require support and sometimes counselling. Teachers can act as counsellors by offering emotional support to TB children through listening, touching and through their physical presence.

\section{Category 4: Traditional healers}

Traditional healers emerged as the fourth category, and encourage compliance emerged as a subcategory of the category.

\section{- $\quad$ Encourage compliance}

The participants expressed the need to involve traditional healers in the discharge plan of patients who consult them. They mentioned that:

"Culturally patients prefer traditional healers..."

Traditional healers play an important role in the South African context. Because South Africa is a diverse nation, nurses must be sensitive and accommodative to all clients irrespective of their culture, education and creed (Peu, 2000:1). Their nursing care should focus on the provision of congruent healthcare. Patients have rights and choices with regard to their health. They have the right to consult Western or traditional healers. The only way to ensure that congruent healthcare is provided is through collaborative efforts with these healers.
Both traditional healers and nurses should be educated on both Western and traditional methods of dealing with the TB epidemic. Consensus can be reached about TB patients' compliance to TB treatment. Another area in which traditional healers, who are supportive of patients suffering from TB, can play a role is the DOTS course (SANTA, 2001:23).

\section{Theme 3: Co-existence of TB and HIV infections}

The third theme that emerged was the co-existence of TB and HIV infections. Two categories, namely TB patients and breast-feeding, emerged from this theme.

\section{Category 1: TB patients}

The subcategory emotional support by nurses emerged from the category of TB patients. The respondents mentioned the problems of these patients in connection with compliance.

\section{- $\quad$ Emotional support}

The following quotations are relevant: "No, I wouldn't take it because I am HIV positive. I do not have to take treatment because I am dying." "Patients must know that they can take anti-retroviral treatment together with TB treatment."

"Patients need to know that TB treatment is effective even when they are HIV positive."

Lewis et al. (2004:605) mention that patients on anti-retroviral drugs for HIV should not take Rifampicin, as it can impair the effectiveness of the drugs. They are given another Tuberculostatic, which will not bring any alteration in drug interaction. Schilling and Cann (2003:389) note that patients should eat balanced meals to promote recovery. They emphasise that nurses must teach patients about the adverse effects of medication and warn patients to report fatigue, weakness and other signs and symptoms with which they might experience.

\section{Category 2: Breast-feeding}

In South Africa, baby-friendly hospital initiatives encourage breast-feeding. Breast-feeding is also promoted at antenatal clinics. This is because breastfeeding reduces mortality and morbidity rates among infants. De Haan (2003:194) states that the milk of every mammal is designed to meet the particular needs of its young; therefore, it stands to reason that breast milk is the perfect food for the human baby and contains all the nutrients which it requires, in the correct proportion.

In support of the above discussion, Young, Van Niekerk and Mogotlane (2003:549) argue that diarrhoea and vomiting in infants and young children are often as a result of the inadequate hygiene of feeding bottles. When infants are breast-fed, the question of the hygiene of feeding bottles does not arise. The promotion of breast-feeding is an important priority for health workers, particularly in poor rural communities. Because these communities are poor, they may not have access to a clean water supply or mothers may not afford formula milk. In reference to the breastfeeding, babies who are infected by HIV/AIDS through mother-to-child transmission via breastfeeding, may be at risk to be given breast milk (van Dyk 2005: 32-33). If the child is at risk, other options such as exclusive breastfeeding and expression and pasteurisation of breast milk are considered (van Dyk 2005: 32 33).

\section{Theme 4: Knowledge of continuous laboratory investigations}

The last theme that emerged was knowledge of continuous laboratory investigations. This was further categorised into knowledge for nurses, TB patients and families.

\section{Category 1: Nurses}

The participants identified the need to educate clinic nurses about informing patients of laboratory investigations conducted during the treatment regime. They said that:

"Patients need to know' that after tw'o months of taking TB treatment they should have their sputum investigated."

"Liver function test is done every month to investigate overloading done to the liver by TB treatment"

Wong (2003:1375) states that nurses assume several roles in the management of TB, including that of helping the family to understand the rationale for diagnostic procedures, assisting with radiographic examinations, performing skin tests and obtaining specimens for laboratory examination. In case of a child, the nurses must calm parental anxieties by dealing 
with the illness constructively and in collaborating in planning the child's continued care (Wong 2003:1375). Nurses should emphasise compliancy regarding medicine (Wong 2003:1105). Nurses should encourage adherence to prescribed medication regimen for TB in order to decrease the opportunities for transmission of the disease (Allender \& Spradley, 2005:211) and to the progression to MDR TB.

\section{Category 2: TB patients}

The category TB patients emerged from the theme of knowledge of continuous laboratory investigations. From the category TB patients, the subcategory blood, sputum and $\mathrm{X}$-ray tests emerged.

- $\quad$ Blood, sputum and x-ray tests

The participants emphasised that:

"We do investigations when the patient is on TB treatment. We usually take sputum; after two months being on treatment we take patient's sputum; after six months we take the sputum again to see whether the patient has been cured or what."

The family has the constitutional right to access information (South Africa, 1996). Their understanding of TB as a disease will enhance their coping skills. The family also needs to know about $x$-rays and sputum tests, which they, as contacts, must undergo. Shannon et al. (2004:1382) state that periodic liver function tests are done for patients with hepatic diseases. Patients' Prothrombin indices are checked, as this is necessary to establish and maintain the required anti-coagulant blood levels to prevent severe episodes of haemorrhage. Harmening (2002:663-664) confirmed that Prothrombin indices are checked once a month or if there are some indicative signs. The acceptable range of PI is 11.1 to 14.1 (Harmening, 2002:663-664).

\section{Recommendations}

The following recommendations were developed from the study:

- $\quad$ Family members should actively participate in the planning and implementation of the discharge plan, as well as the administration of TB treatment.
The DOTS strategy should be adopted in order to provide comprehensive treatment to TB patients. The DOTS strategy should also be explained in rural homes.

- $\quad$ Prevention of MDR TB should be emphasised to all patients on treatment for TB.

- $\quad$ The Government should support the district hospitals in discharge planning by providing the necessary facilities.

- $\quad$ Nurses who work with TB patients should receive regular in-service training.

- Community members should be empowered through the acquisition of knowledge about TB and HIV/Aids, so that they can serve as the extended arms of clinics and hospitals.

\section{Conclusion}

The objective of the study was to explore and describe the views of nurses working with TB patients at a district hospital in the North-West Province. The research process followed a qualitative research design and looked at the question "What are the opinions of nurses working with $T B$ patients regarding a hospital discharge plan at George Stegmann Hospital in the Moses Kotane Local Municipality district, North-West Province?". In the focus group interviews, the participants revealed both positive and negative opinions regarding discharge plans. The data were classified into themes, categories and subcategories. The participants' suggestions regarding discharge plans were addressed and discussed. The main discussions focused on the need for patient education on compliance and patient involvement. Finally, recommendations were disseminated to concerned authorities.

\section{References}

ALLENDER, JA \& SPRADLEY, BW

2005: Community health nursing. Philadelphia: Wolters.

BABBIE, E \& MOUTON, J 2001: The practice of social research. Cape Town: Oxford University Press.

BABBIE, E \& MOUTON, J 2007: The practice of social research. Cape Town: Oxford University Press.

BARNHART, RK 1996: The world book dictionary (vol. 1). Chicago: Scott Fetzer.

BLESS, C \& SMITH, CH 2004: Fundamental of social research methods. $3^{\text {rd }}$ Edition. Cape Town: Juta.

BURNS, N \& GROVE, SK 2003: The practice of nursing research: conduct, critique and utilization. Philadelphia: WB Saunders.

CLEMEN-STONE,S; MCGUIRE,SL \& EIGSTI, DG 2002: Comprehensive Community Health Nursing: Family, Aggregate \& Community Practice. St. Louis:Mosby.

CRESWELL, JW 2003: Research design: qualitative, quantitative, mixed methods approaches. Thousand Oaks: Sage Publications.

DE HAAN, M 2001: The health of Southern Africa. $2^{\mathrm{ND}}$ Edition. Cape Town: Juta.

DE VOS, AS 2001: Research at grass roots: a primer for the caring professions. Pretoria: Van Schaik.

IENNII L, K; KING,L\&SWANEPOEL, T 2005: Aspects of primary health care. Johannesburg: Thompson.

HARMENING, DM 2002: Clinical haematology and fundamentals of hemostasis. $4^{\text {th }}$ Edition. Philadelphia: F.A. Davis Company.

JOUBERT, G \& EHRLICH, R Epidemiology: a research manual for South Africa. $2^{\text {nd }}$ Edition. Cape Town: Oxford University Press.

KARIM, SS \& KARIM, Q 2005: HIV/ AIDS in South Africa. Cape Town: Cambridge University Press.

KIBEL, MA \& WAGSTAFF, LA 2003: Child health for all. Cape Town: University Press.

KOZIER, B; ERB, G; BERMAN, A \& SNYDER, S 2004: Fundamental of Nursing. Menlow-Park, California: Alexander. DIRKSEN, SR 2004: Medical-surgical 
nursing. St Louis: CV Mosby.

LUNDY, KS \& JANES, S 2001: Community health nursing: Caring for the public's health. Barb Mews: Jones and Barlett Publishers.

MULDER, M 2004: Practical guide for general nursing science (part 1). Cape Town: Kagiso.

PEARSON, L 2002: Nurse practioners' drug hand book. $4^{\text {th }}$ Edition. Philadelphia: JB Lippincott.

PEU, MD 2000: The attitude of community health nurses toward the integration of traditional healers in primary health care in the North-West Province. Unpublished MA Cur dissertation. Pretoria: University of South Africa.

PHIPPS, M \& SANDS, MN 2003: Medical - Surgical Nursing: Health and illness perspective. $7^{\mathrm{TH}}$ Edition. St. Louis: Mosby.

PILLITERI, A 2003: Maternal and child health nursing. Philadelphia: JB Lippincott.

POLIT, DF; BECK, CT \& HUNGLER, BP 2001: Essentials of nursing research. Philadelphia: Williams \& Wilkins.

\section{SANTA see SOUTH AFRICAN NATIONAL TUBERCULOSIS ASSOCIATION}

SCHILLING, MC \& CANN, JA 2003: Best practices: a guide to excellence in nursing care. Philadelphia: JB Lippincott.

SHANNON, MT; WILSON, BA. \& STANG, CL 2004: Health professional drug guide. New Jersey: Prentice Hall

SOUTH AFRICA 1996: The Constitution of the Republic of South Africa, Act 108 of 1996 (Section 32). Pretoria: Government Printer.

\section{SOUTHAFRICA, DEPARTMENT OF} HEALTH 2000b: The South African Tuberculosis Control Programme Practical Guidelines. Cape Town: Government Printer.

\section{SOUTH AFRICA, DEPARTMENT OF} HEALTH 2002: National Tuberculosis Control Programme: George Stegmann Hospital Statistics register for tuberculosis patients. Johannesburg:
Government Printer.

SOUTH AFRICA, DEPARTMENT OF

HEALTH 2006: National Tuberculosis Control Programme: George Stegmann Hospital Statistics register for tuberculosis patients. Johannesburg: Government Printer.

SOUTH AFRICA, DEPARTMENT OF HEALTH 2005: HIV and Tuberculosis. Khomanani News, 8(no issue number): p2-3.

SOUTH AFRICAN NATIONAL TUBERCULOSIS ASSOCIATION 2001: TB and Health News, 40(3):p1-23.

STANHOPE, M \& LANCASTER, J 2000: Community public health nursing. St. Louis: CV Mosby.

VAN DYK, A 2005: HIV/AIDS care counselling: a multidisciplinary approach. Cape Town: Pearson Education.

VAN WYK, NC 2005: Can traditional medicine be part of our health care system? Nursing update, 29(10): 36-7.

VLOK, ME 2006: Manual of community nursing and communicable diseases. $5^{\text {th }}$ Edition. Cape Town: Juta.

WONG, DL 2003: Nursing care of infants and children. St. Louis: CV Mosby.

YOUNG, A; VAN NIEKERK, CF \& MOGOTLANE, S 2003: Manual of nursing. Lansdowne: Juta. 